\title{
Localization of Xyloglucan Epitopes in the Gelatinous Layer of Developing and Mature Gelatinous Fibers of European Aspen (Populus tremula L.) Tension Wood
}

\author{
Jong Sik Kim, ${ }^{\mathrm{a}, \mathrm{b}}$ and Geoffrey Daniel ${ }^{\mathrm{a}, *}$ \\ There is controversy concerning the presence of xyloglucans in gelatinous \\ (G) layers of Populus spp. tension wood, particularly in mature G-fibers. \\ Transmission electron microscopy (TEM) immunogold localization \\ combined with LM15 antibody (recognizes XXXG-motif of xyloglucans, \\ heptasaccharide) was used to investigate the distribution of xyloglucan \\ epitopes in both transverse and radial sections of $P$. tremula tension wood. \\ Results provided clear evidence for the presence of xyloglucans in both \\ mature and developing G-layers. Developmental decrease of LM15 \\ epitope localization in G-layers was also detected during G-fiber \\ maturation. High magnification TEM observations showed specific \\ localization of LM15 epitopes on newly synthesized cellulose macrofibrils \\ present in the innermost layer of developing G-layers adjacent to the cell \\ lumen, suggesting linkage between xyloglucans and cellulose macrofibrils. \\ Possible mechanisms were discussed for developmental changes of \\ xyloglucan with respect to the different results reported in the literature.
}

Keywords: Gelatinous layer; Immunolocalization; LM15 antibody; Populus tremula; Tension wood; Xyloglucan

Contact information: a: Wood Science, Department of Forest Biomaterials and Technology, Swedish University of Agricultural Sciences, P.O. Box 7008, SE-750 07 Uppsala, Sweden; b: Department of Wood Science and Engineering, Chonnam National University, Gwangju, 61186, Republic of Korea;

*Corresponding author: geoffrey.daniel@slu.se

\section{INTRODUCTION}

Gelatinous $(\mathrm{G})$ fibers are a unique cell type found in tension woods that are formed in leaning stems and branches of hardwoods (Gardiner et al. 2014; Donaldson and Singh 2016). Although many hardwood species have no G-fibers in tension wood, G-fiber formation is generally thought of as a prominent feature of tension woods (Fisher and Stevenson 1981; Clair et al. 2006; Gardiner et al. 2014; Donaldson and Singh 2016). Gfibers are characterized by the formation of a G-layer adjacent to the cell lumen (Fisher and Stevenson 1981) and are typically classified into three types, $S_{1}+G, S_{1}+S_{2}+G$, and $S_{1}+S_{2}+S_{3}+G$ (Wardrop and Dadswell 1955; Saiki and Ono 1971; Ghislain and Clair 2017). In Populus tremula L., the G-layer replaces part of the $S_{2}$ layer and the entire $S_{3}$ layer (Kim and Daniel 2012).

Compared to normal fibers, G-fibers are well known to contain more cellulose, but less lignin and xylans (Pilate et al. 2004; Gorshkova et al. 2010) because the G-layers are composed predominantly of cellulose. Tension wood is known to show much greater tensile stress than normal woods, which is thought developed at the tissue and fiber levels through changes in G-layer swelling (i.e. lateral pressure on surrounding secondary cell walls) and/or G-layer shrinkage (i.e. via changes in molecular interactions between cellulose and matrix polysaccharides) (reviewed by Donaldson and Singh 2016). With 
advances in understanding G-layer chemistry, it has been proposed that non-cellulosic polysaccharides of the G-layer are involved in tensile stress generation in G-fibers (Mellerowicz and Gorshkova 2012). In particular, xyloglucans have frequently been implicated in the generation of tensile stress in G-fibers (Nishikubo et al. 2007; Mellerowicz et al. 2008; Baba et al. 2009; Kaku et al. 2009; Mellerowicz and Gorshkova 2012). However, the distribution and amount of xyloglucans have been reported to vary greatly between studies, depending on the methods of analysis including chemical analysis, immunofluorescence, immunogold-silver staining, and scanning electron microscopy or transmission electron microscopy (SEM, TEM) (Nishikubo et al. 2007; Bowling and Vaughn 2008; Mellerowicz et al. 2008; Baba et al. 2009; Sandquist et al. 2010; Gorshkova et al. 2015; Guedes et al. 2017). For example, Nishikubo (2007) reported the presence of xyloglucans in $P$. alba, $P$. tremula, and hybrid aspen (P. tremula $\times P$. tremuoides) using chemical analysis (showing $10 \%$ to $15 \%$ of the total dry weight) and immunocytochemistry. In contrast, Guedes et al. (2017) reported no evidence of the presence of xyloglucans in hybrid poplar $(P$. tremula $\times P$. alba $)$ using an immunocytochemical study combined with various antibodies. Alméras and Clair (2016) also suggested that xyloglucan-mediated tensile stress generation in G-layers can be rejected because xyloglucans are not actually localized in G-layers. Therefore, an in-depth immunocytochemical study of xyloglucans in G-layers (i.e., early to mature stages of Glayer formation) is necessary to obtain a more complete understanding of xyloglucan distribution in G-layers and thereby help understand its function in the generation of tensile stress in G-layers.

In this study, the authors report the spatial microdistribution of LM15 epitopes (recognizing XXXG motifs of xyloglucans, heptasaccharide) in G-layers of $P$. tremula during G-fiber formation using TEM immunogold labeling. To evaluate the possibility of differences in antibody accessibility depending on fiber wall orientation, both transverse (cross)- and radial (longitudinal) sections were observed. This study was primarily designed to improve the understanding of inconsistency with observations of xyloglucan distribution in G-layers of Populus spp.

\section{EXPERIMENTAL}

\section{Plant Materials, Fixation, and Embedding}

Wood discs were taken from a stem of 10-year-old leaning poplar tree (Populus tremula L.) grown in the field (Uppsala, Sweden) on August 16 (Kim and Daniel 2012). A tree was naturally inclined to $c a .40^{\circ}$ from the vertical and was $c a .7 .1 \mathrm{~cm}$ in diameter (4.3 $\mathrm{cm}: 2.3 \mathrm{~cm}=$ TW: opposite wood). Small sectors were cut from the tension wood and fixed within a mixture of $2 \% \mathrm{v} / \mathrm{v}$ paraformaldehyde and $2.5 \% \mathrm{v} / \mathrm{v}$ glutaraldehyde in a 0.05 $\mathrm{M}$ sodium cacodylate buffer ( $\mathrm{pH}$ 7.2) for $4 \mathrm{~h}$ at room temperature (Kim and Daniel 2012). After dehydration through a graded ethanol series, sectors were embedded in LR White resin (London Resin Company Ltd., Basingstoke, UK) as previously described (Kim and Daniel 2012). All chemicals used in the study were purchased from Sigma-Aldrich (St. Louis, MO, USA), unless otherwise noted. 


\section{Methods}

\section{TEM and immunocytochemistry analysis}

For TEM immunogold labeling, transverse- and radial ultrathin sections (ca. $90 \mathrm{~nm})$ mounted on nickel grids were incubated with the LM15 antibody (Marcus et al. 2008) (PlantProbes, Leeds, UK), followed by incubation with anti-rat secondary antibody labeled with 10-nm colloidal gold particles (BBInternational, Cardiff, UK) (Kim and Daniel 2012). Grids were examined with a Philips CM12 TEM (Philips, Eindhoven, Netherlands) after post-staining with $4 \% \mathrm{w} / \mathrm{v}$ aqueous uranyl acetate. Negative TEM films were scanned using an Epson Perfection Pro 750 film scanner (Epson, Nagoya, Japan). Images were contrasted using Adobe Photoshop CS6 (version 13; San Jose, CA, USA). Results reflect observations on two transverse and two radial sections prepared from four different embedded blocks. For observations of tension wood (TW) formation, some semi-thin resin sections $(\mathrm{ca} .1 \mu \mathrm{m})$ were stained with $1 \% \mathrm{w} / \mathrm{v}$ toluidine blue (in $0.1 \%$ boric acid) and examined using a Leica DMLB light microscope (Leica, Wetzlar, Germany) equipped with an Infinity X-32 digital camera (Deltapix, Samourn, Denmark).

\section{RESULTS AND DISCUSSION}

Using immunolocalization methods, this study provides information on the distribution of LM15 xyloglucan epitopes in poplar TW fiber cell walls, with particular focus on G-layers. For a clearer comparison of results from other studies performed on other Populus spp., there are certain aspects that need to be considered in the following results and discussion. First, the TW samples studied were collected near the end of a growing season, i.e. TW fibers studied contain G-fibers from both latewood (1 to 2 cells from cambium) and earlywood. Second, the wood samples studied are collected from an outdoor-grown juvenile poplar tree that was naturally leaning for several years. Third, mature TW fibers in the study represent fully developed G-fibers (i.e. the absence of cytoplasm) within a current growth ring, i.e. fibers developed from previous growth rings were not studied.

Numbers marked in cells (e.g. GF-1 and GF-2 in Fig. 2) indicate approximate locations of G-fibers from cambium, which was identified on radial sections using TEM observations. Higher number in images indicates greater maturity of G-fibers. No contribution of non-specific background labeling was detected in control sections with the primary antibody omitted (not shown).

No noticeable difference was detected in the localization of LM15 epitopes between the transverse- and radial orientations for either developmental or mature stages of Glayers. This result reduces the possibility of differences in antibody accessibility in Glayers depending on fiber wall orientation (i.e., cross vs. longitudinal).

G-layer formation was observed in G-fibers across developing and mature xylem (Fig. 1a), in which a part of $S_{2}$ including the entire $S_{3}$ layer was replaced by the G-layer (arrowheads, inset in Fig. 1a). Epitopes were first detected in G-layers at early stages of formation (Figs. 1b and 2a). During G-layer development, xyloglucan epitopes were found randomly across G-layers (Figs. 1c, d and 2b, c) but gradually decreased (Fig. 3). 


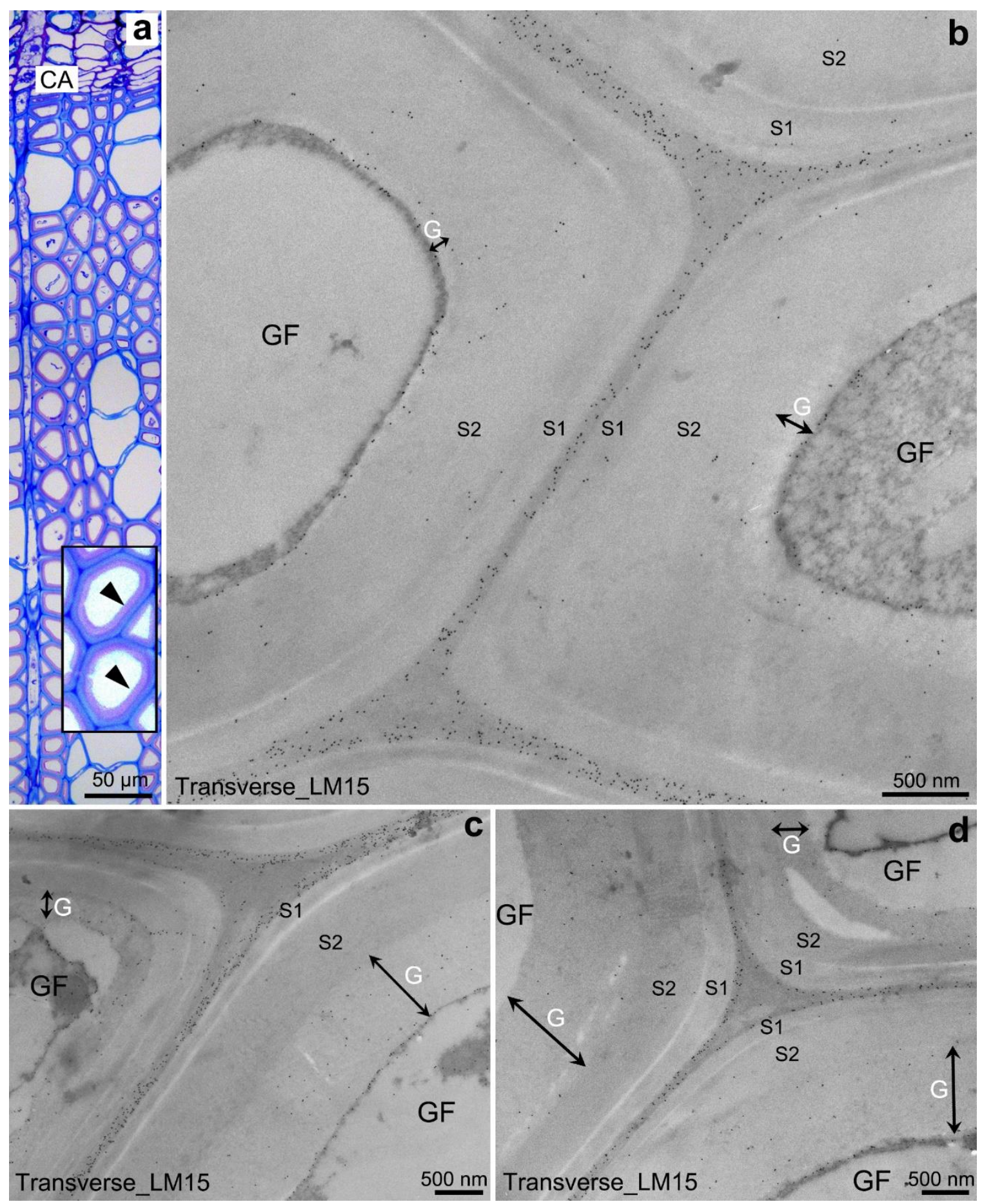

Fig. 1. Immunogold localization of LM15 epitopes on transverse sections of developing and mature G-fibers: a) $P$. tremula tension wood showing the formation of G-layers stained pink with toluidine blue. Arrowheads in inset indicate G-layer formation in mature G-fibers; b) distribution of epitopes in G-layers (G, double headed arrows) at early stages of G-layer formation. Note: epitope distribution in $S_{1}$ and $S_{2}$ layers of $G$-fibers (GF); c) and d) Distribution of epitopes in $\mathrm{G}$-layer $(\mathrm{G})$ at advanced stages of $\mathrm{G}$-layer formation development. Note: epitope distribution in the boundary between the G-layer and the cytoplasm (or innermost G-layer), $C A=$ cambium cell 


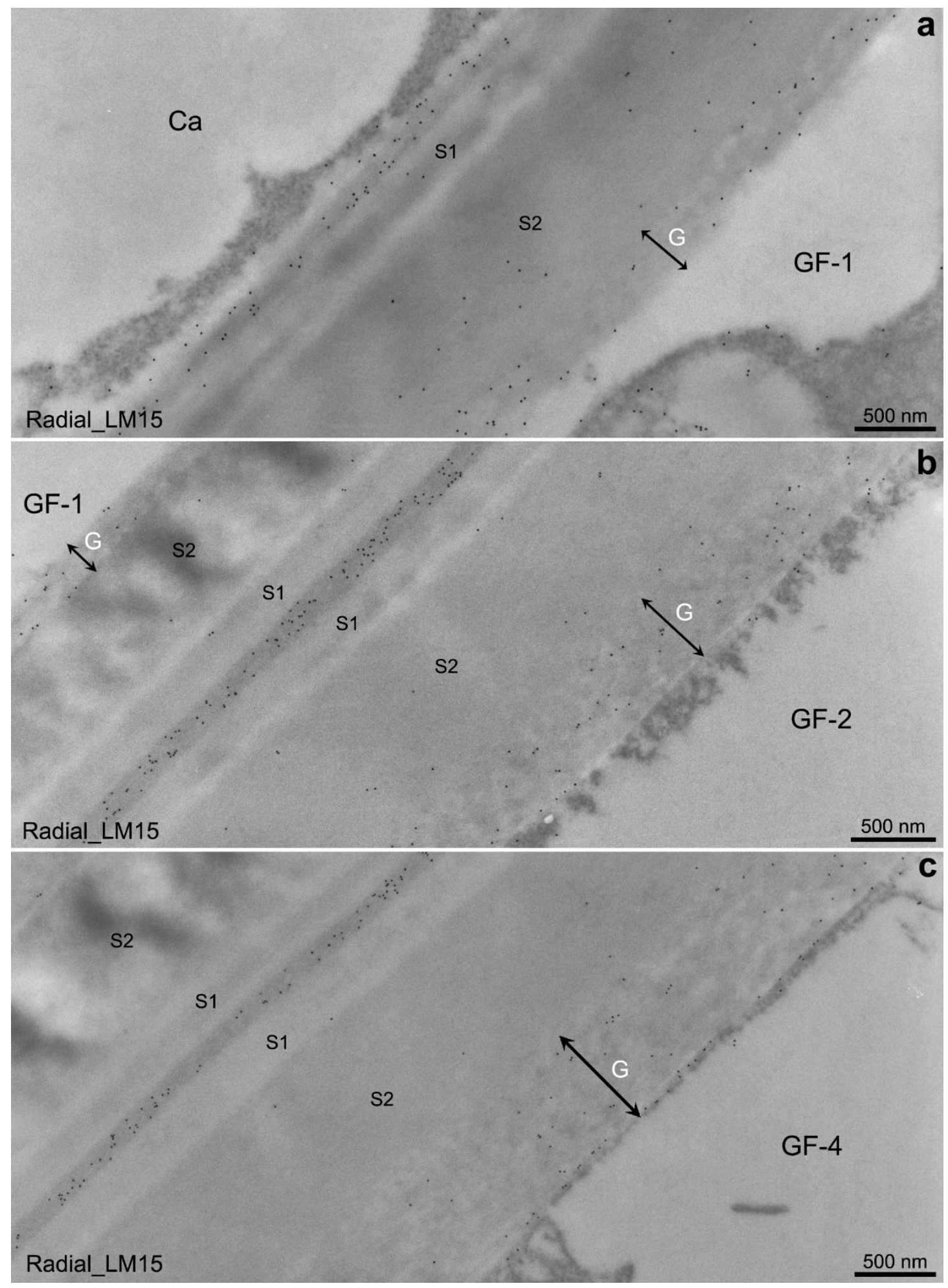

Fig. 2. Immunogold localization of LM15 epitopes on radial sections of early stages of G-fiber formation: a) through c) each image indicates first (GF-1), second (GF-2), and fourth (GF-4) Gfibers from cambium cells $(\mathrm{Ca})$, respectively (see Fig. 1a). The LM15 epitopes were detected across developing $\mathrm{G}$-layers ( $\mathrm{G}$, double headed arrows). Note: epitope distribution in $\mathrm{S}_{1}$ and $\mathrm{S}_{2}$ layers of $\mathrm{G}$-fibers $(\mathrm{a}, \mathrm{b})$ and in the boundary between the G-layer and the cytoplasm (c). 


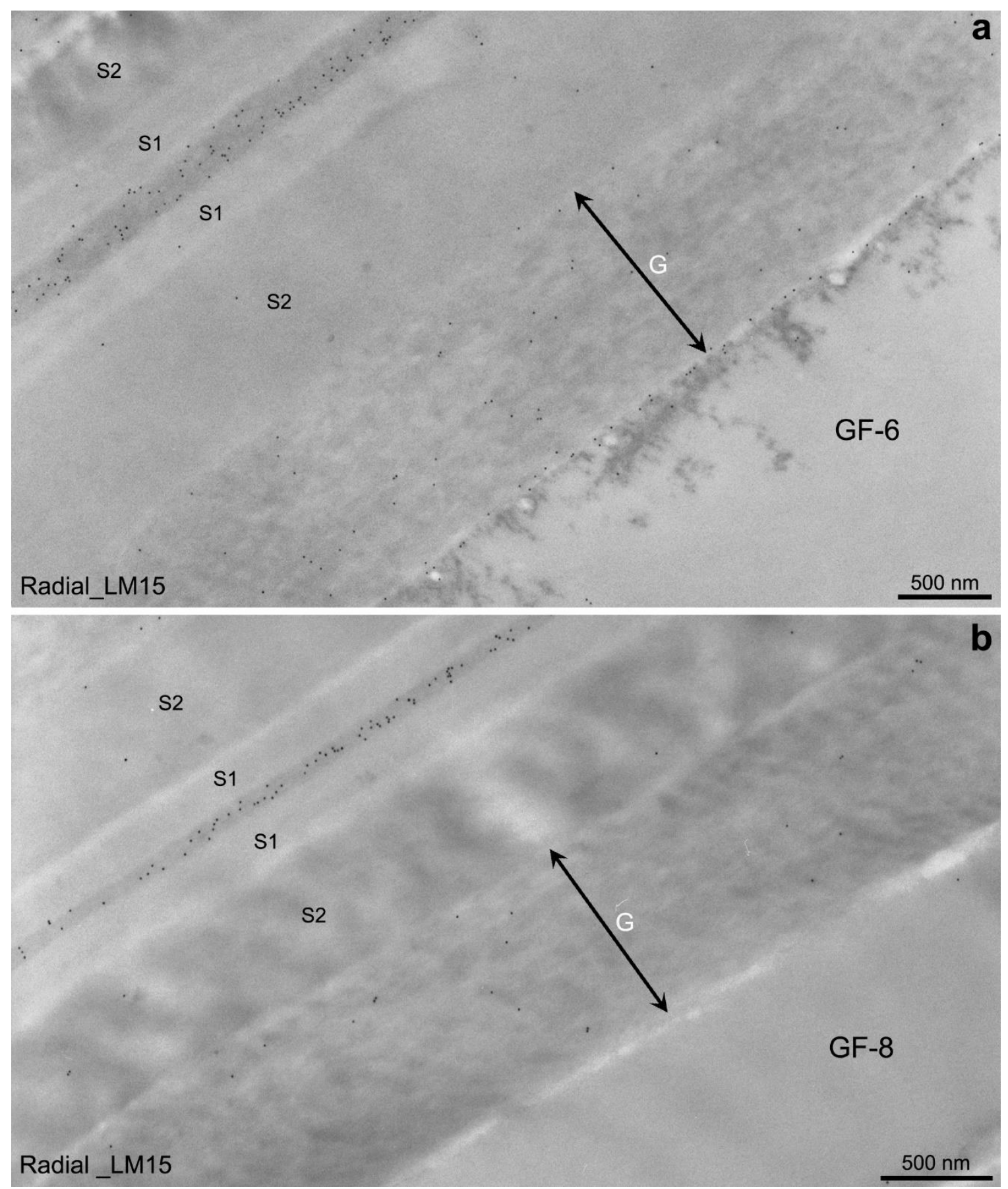

Fig. 3. Immunogold localization of LM15 epitopes on radial sections of late stages of G-fiber formation: a) and b) each micrograph indicates sixth (GF-6) and eighth (GF-8) G-fibers from cambium cells, respectively (Fig. 1a). The amount of LM15 epitopes detected gradually decreased in G-layers (G, double headed arrows) at late stages of G-layer formation. Note: epitope distribution in the boundary between the G-layer and the cytoplasm (a) 


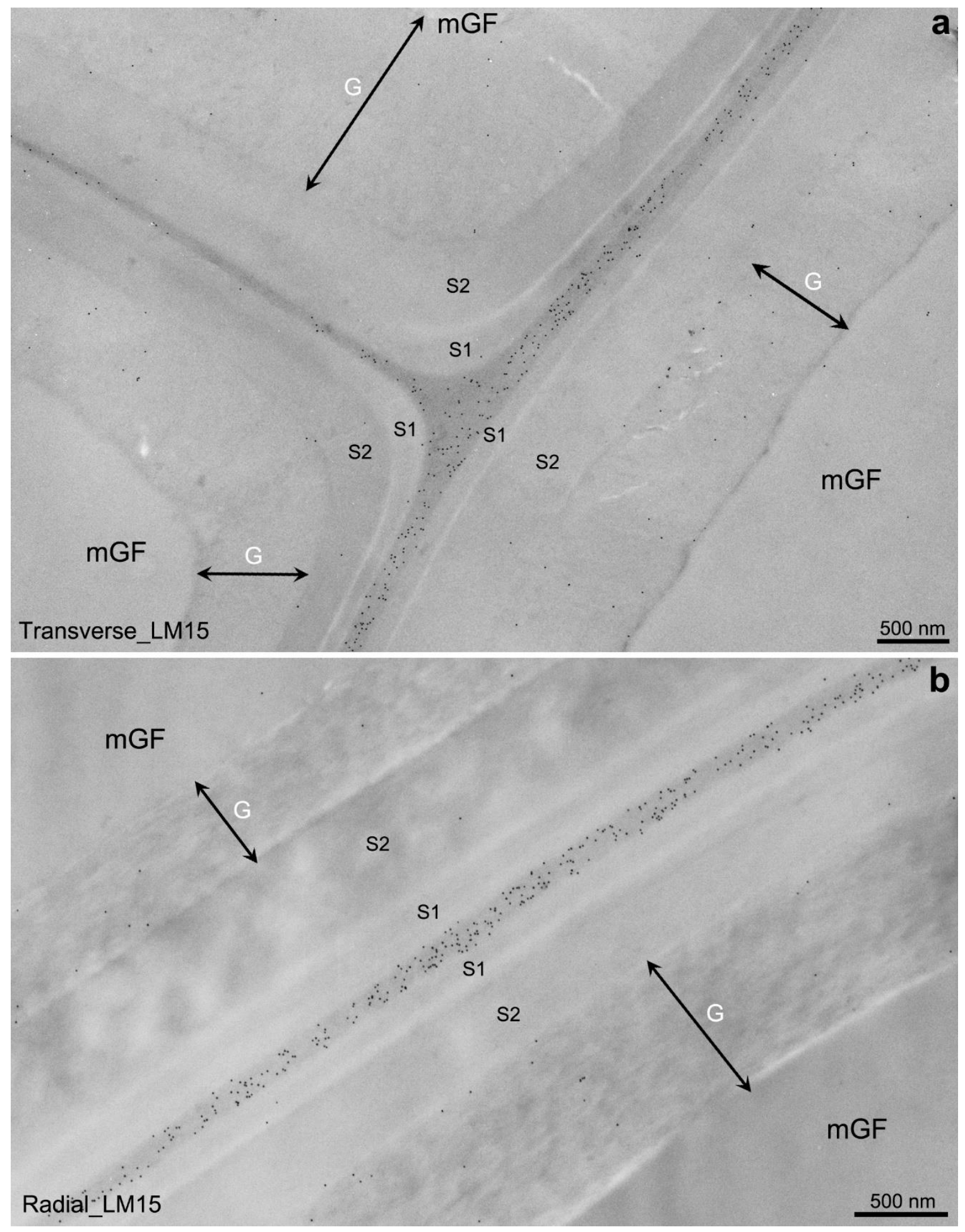

Fig. 4. Immunogold localization of LM15 epitopes in mature G-fibers (mGF): a) and b) transverse and radial sections, respectively. Epitopes were sparsely distributed in mature G-layers (G, double headed arrows) with considerable variation in amounts of epitopes labeled. Note: absence of epitope labeling in $S_{1}$ and $S_{2}$ layers of mature $\mathrm{G}$-fibers 


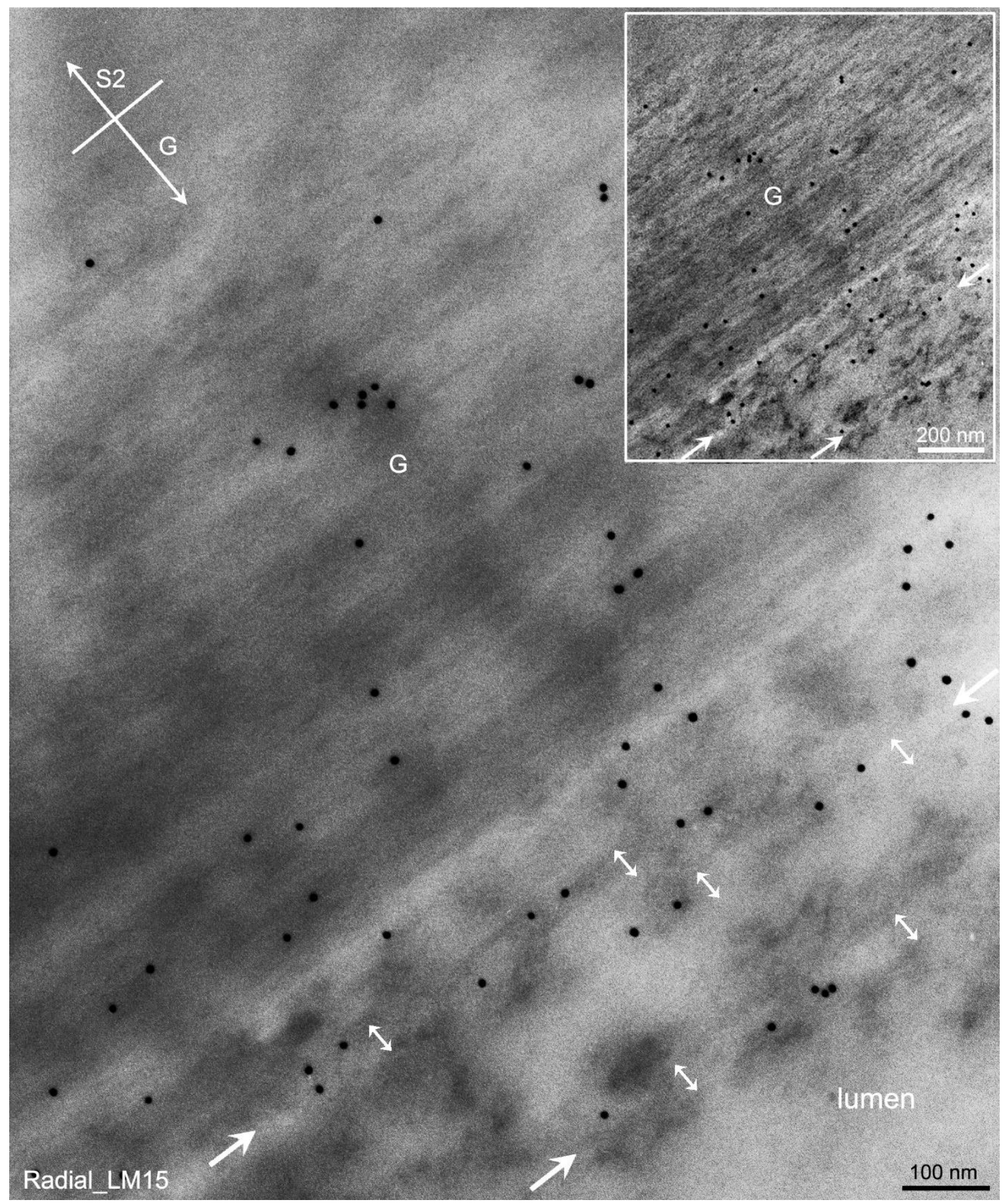

Fig. 5. High magnification $(60,000 \times)$ image of LM15 epitope localization on radial section of a developing G-fiber (GF-6); epitopes specifically localized on the newly synthesized cellulose macrofibrils (arrows) of ca. $40 \mathrm{~nm}$ diameter (double headed arrows). Note: inset shows highly contrasted images using Photoshop.

These results were consistent with previous immunocytochemical studies of Glayers in Populus spp. including P. tremula (Nishikubo et al. 2007) and P. alba (Baba et al. 2009) by CCRC-M1 and hybrid aspen (P. tremula $\times$ P. tremuoides) using CCRCM1 and CBM FXG-14b (Sandquist et al. 2010). However, results differ from the study of hybrid poplar (P. tremula $\times P$. alba) (Guedes et al. 2017) that show an absence of 
xyloglucan epitopes in developing G-layers labeled with different antibodies, including LM15 used in this study. With maturity of G-fibers, epitopes were sparsely distributed in G-layers with considerable variations observed between the G-fibers (Fig. 4). This result differs from previous studies that report an absence of xyloglucan epitopes in G-layers of mature G-fibers $P$. tremula (Nishikubo et al. 2007) and hybrid poplar (Guedes et al. 2017). Unlike previous results (Nishikubo et al. 2007; Sandquist et al. 2010), no specific (or abundant) epitope distribution was detected in the boundary between the S2- and Glayers during G-layer development (Figs. 1 through 4).

During G-layer formation, epitopes were readily detected in the cytoplasm, particularly at the boundary with G-layers (or the innermost layer of G-layers) (Figs. 1b to 1d, 2c, and 3a). At high magnification, these epitopes were specifically localized on newly synthesized cellulose macrofibrils (i.e., microfibril aggregations) of $c a .40 \mathrm{~nm}$ diameter (Fig. 5). This result clearly illustrates the association between xyloglucans and cellulose macrofibrils (i.e., surface binding) during G-layer formation. Baba et al. (2009) proposed that xyloglucans bound to cellulose macrofibrils allow cross-linking of newly synthesized cellulose macrofibrils to pre-existing macrofibrils during development of the G-layer.

Consequently, the results indicated that xyloglucans were a component in both developing and mature G-layers of $P$. tremula. Observations also demonstrated that there were developmental changes of xyloglucan epitopes in G-layers during G-fiber maturation, i.e., gradual decrease of LM15 xyloglucan epitopes in G-layers. There are several possible explanations for these developmental changes. Considering the authors' results and the available literature, the following possibilities were considered:

1) Migration of xyloglucans that were deposited initially in G-layers to compound middle lamellae (CML) during G-fiber maturation and thereby xyloglucan was decreased in G-layers. In normal fibers of hybrid aspen, Bourquin et al. (2002) proposed that xyloglucan deposition in CML continued during formation of a secondary cell wall, i.e., transportation of xylogucans from the cytoplasm to CML via secondary cell walls. This study also showed specific localization of LM15 epitopes in $S_{1}$ and $S_{2}$ layers of Gfibers and its decrease during G-fiber formation (Figs. 1b through 1c, and 2). Yoshinaga et al. (2012) reported that lignification of the CML continues progressively during G-layer formation, i.e., penetration of monolignols through the $\mathrm{S}_{1}$ and $\mathrm{S}_{2}$ layers during G-fiber formation is possible.

2) A decrease in antibody accessibility following xyloglucan endo-transglycosylase (XET) mediated xyloglucan rearrangement in G-layers during G-fiber maturation. Nishikubo et al. (2007) reported activity of XET in developing G-layers of several Populus spp. Because several different types of motifs (oligosaccharides) have been demonstrated in the structure of xyloglucans (Fry et al. 1993), it can be expected that xyloglucan rearrangement in G-layers followed by changes in the chemical structure of xyloglucans, which will be less labeled by LM15 (i.e., it only recognizes XXXG motif xyloglucans, heptasaccharides). However, the 30 commercial antibodies specific to xyloglucans, including LM15, were recently tested by Guedes et al. (2017), but none of these antibodies labeled mature hybrid poplar G-layers.

3) Masking of epitopes following the entrapment of xyloglucans during cellulose aggregation in G-layers. Mellerowicz et al. (2008) proposed that xyloglucan may be entrapped inside nascent cellulose macrofibrils of the G-layer during maturation, thereby inducing longitudinal tensile stress within macrofibrils. This entrapment can possibly make xyloglucans inaccessible to antibodies (Mellerowicz et al. 2008). 
Although there is controversy for such an entrapment model (Alméras and Clair 2016) and the presence of xyloglucans in G-layers of Populus spp. (Guedes et al. 2017), this study provided microscopy evidence that xyloglucans are a component of G-layers of $P$. tremula both in developing and mature G-fibers.

4) Finally, there is possibility of enzymatic degradation of xyloglucans in G-layers during G-fiber maturation. Enzymatic degradation of cell wall components including pectins, xyloglucans, and galactoglucomannans by activity of hydrolases in bordered pit membranes during maturation has been proposed in several tree species including Populus spp. (O'Brien and Thimann 1967; O'Brien 1970; Morrow and Dute 1998; Kim et al. 2011; Kim and Daniel 2013). The only difference from pit membranes is that xyloglucans are still present even in fully matured G-layers of $P$. tremula. No pectin, xyloglucan, and galactoglucomannan epitopes are detected in fully matured bordered pit membranes even though epitopes were present in developing stages (Kim et al. 2012; Kim and Daniel 2013).

\section{CONCLUSIONS}

1. The TEM immunolocalization of LM15 epitopes indicated that xyloglucans were a component of G-layers in both developing and mature G-fibers of P. tremula tension wood.

2. High resolution TEM images indicated that xyloglucans are probably linked to cellulose macrofibrils during G-layer formation.

3. Results indicated a developmental decrease of LM15 epitopes in G-layers. At present, the mechanism of this decrease is unclear, and it could be a key factor to clarify whether xyloglucans are involved in the generation of tensile stress in G-layers of poplar tension wood.

\section{ACKNOWLEDGMENTS}

This work was supported by the National Research Foundation of Korea (NRF), a grant funded by the Korean government (MSIP) (No. NRF-2018R1C1B5086602), and Formas projects 2008-1399, 2009-582, 2011-416, and 2015-469.

\section{REFERENCES CITED}

Alméras, T., and Clair, B. (2016). "Critical review on the mechanism of maturation stress generation in trees," J. R. Soc. Interface 13(122), Article ID 20160550. DOI: 10.1098/rsif.2016.0550

Baba, K., Park, Y. W., Kaku, T., Kaida, R., Takeuchi, M., Yoshida, M., Hosoo, Y., Ojio, Y., Okuyama, T., Taniguchi, T., et al. (2009). "Xyloglucan for generating tensile stress to bend tree stem," Mol. Plant 2(5), 893-903. DOI: 10.1093/mp/ssp054

Bourquin, V., Nishikubo, N., Abe, H., Brumer, H., Denman, S., Eklund, M., Christiernin, M., Teeri, T. T., Sundberg, B., and Mellerowicz, E. J. (2002).

"Xyloglucan endotransglycosylase have a function during the formation of secondary 
cell walls of vascular tissues," Plant Cell 14(12), 3073-3088. DOI:

$10.1105 /$ tpc. 007773

Bowling, A. J., and Vaughn, K. C. (2008). "Immunocytochemical characterization of tension wood: Gelatinous fibers contain more than just cellulose," Am. J. Bot. 95(6), 655-663. DOI: 10.3732/ajb.2007368

Clair, B., Ruelle, J., Beauchêne, J., Prévost, M. F., and Fournier, M. (2006). "Tension wood and opposite wood in 21 tropical rain forest species," IAWA J. 27(3), 329-338. DOI: 10.1163/22941932-90000158

Donaldson, L. A., and Singh, A. P. (2016). "Reaction wood," in: Secondary Xylem Biology, Y. S. Kim, R. Funada, and A. P. Singh (eds.), Academic Press, London, UK, pp. 93-110. DOI: 10.1016/B978-0-12-802185-9.00006-1

Fisher, J. B., and Stevenson, J. W. (1981). "Occurrence of reaction wood in branches of dicotyledons and its role in tree architecture," Int. J. Plant Sci. 142(1), 82-95. DOI: $10.1086 / 337199$

Fry, S. C., York, W. S., Albersheim, P., Darvill, A., Hayashi, T., Joseleau, J.-P., Kato, Y., Lorences, E. P., MacLachlan, G. A., and McNeil, M. (1993). "An unambiguous nomenclature for xyloglucan-derived oligosaccharides," Physiol. Plantarum 89(1), 13. DOI: 10.1111/j.1399-3054.1993.tb01778.x

Gardiner, B., Barnett, J., Saranpää, P., and Gril, J. (2014). The Biology of Reaction Wood, Springer, New York, NY, USA. DOI: 10.1007/978-3-642-10814-3

Ghislain, B., and Clair, B. (2017). "Diversity in the organization and lignification of tension wood fibre walls - A review," IAWA J. 38(2), 245-265. DOI: $10.1163 / 22941932-20170170$

Gorshkova, T. A., Gurjanov, O. P., Mikshina, P. V., Ibragimova, N. N., Mokshina, N. E., Salnikov, V. V., Ageeva, M. V., Amenitskii, S. I., Chernova, T. E., and Chemikosova, S. B. (2010). "Specific type of secondary cell wall formed by plant fibers," Russ. J. Plant Physl. 57(3), 328-341. DOI: 10.1134/S1021443710030040

Gorshkova, T., Mokshina, N., Chernova, T., Ibragimova, N., Salnikov, V., Mikshina, P., Tryfona, T., Banasiak, A., Immerzeel, P., Dupree, P., et al. (2015). “Aspen tension wood fibers contain $\beta$ - $(1 \rightarrow 4)$-galactans and acidic arabinogalactans retained by cellulose microfibrils in gelatinous walls," Plant Physiol. 169(3), 2048-2063. DOI: 10.1104/pp.15.00690

Guedes, F. T. P., Laurans, F., Quemener, B., Assor, C., Lainé-Prade, V., Boizot, N., Vigouroux, J., Lesage-Descauses, M.-C., Leplé, J.-C., Déjardin, A., et al. (2017). "Non-cellulosic polysaccharide distribution during G-layer formation in poplar tension wood fibers: Abundance of rhamnogalacuronan I and arabinogalactan proteins but no evidence of xyloglucan," Planta 246(5), 857-878. DOI: 10.1007/s00425-017-2737-1

Kaku, T., Serada, S., Baba, K., Tanaka, F., and Hayashi, T. (2009). "Proteomic analysis of the G-layer in poplar tension wood," J. Wood Sci. 55(4), 250-257. DOI: $10.1007 / \mathrm{s} 10086-009-1032-6$

Kim, J. S., and Daniel, G. (2012). "Distribution of glucomannans and xylans in poplar xylem and their changes under tension stress," Planta 236(1), 35-50. DOI: $10.1007 / \mathrm{s} 00425-012-1588-\mathrm{z}$

Kim, J. S., and Daniel, G. (2013). "Developmental localization of homogalacturonan and xyloglucan epitopes in pit membranes varies between pit types in two poplar species," IAWA J. 34(3), 245-262. DOI: 10.1163/22941932-00000021 
Kim, J. S., Awano, T., Yoshinaga, A., and Takabe, K. (2011). "Temporal and spatial diversities of the immunolabeling of mannan and xylan polysaccharides in differentiating earlywood ray cells and pits of Cryptomeria japonica," Planta 233(1), 109-122. DOI: 10.1007/s00425-010-1283-X

Marcus, S. E., Verhertbruggen, Y., Hervè, C., Ordaz-Ortiz, J. J., Farkas, V., Pedersen, H. L., Willats, W. G. T., and Knox, J. P. (2008). "Pectic homogalactronan masks abundant sets of xyloglucan epitopes in plant cell walls," BMC Plant Biol. 8, Article No. 60. DOI: 10.1186/1471-2229-8-60

Mellerowicz, E. J., and Gorshkova, T. A. (2012). "Tensional stress generation in gelatinous fibres: A review and possible mechanism based on cell-wall structure and composition," J. Exp. Bot. 63(2), 551-565. DOI: 10.1093/jxb/err339

Mellerowicz, E. J., Immerzeel, P., and Hayashi, T. (2008). "Xyloglucan: The molecular muscle of trees," Ann. Bot. 102(5), 659-665. DOI: 10.1093/aob/mcn170

Morrow, A. C., and Dute, R. R. (1998). "Development and structure of pit membranes in the rhizome of the woody fern Botrychium dissectum," IAWA J. 19(4), 429-441. DOI: $10.1163 / 22941932-90000664$

Nishikubo, N., Awano, T., Banasiak, A., Bourquin, V., Ibatullin, F., Funada, R., Brumer, H., Teeri, T. T., Hayashi, T., Sundberg, B., et al. (2007). "Xyloglucan endotransglycosylase (XET) functions in gelatinous layers of tension wood fibers in poplar - A glimpse into the mechanism of the balancing act of trees," Plant Cell Physiol. 48(6), 843-855. DOI: $10.1093 / \mathrm{pcp} / \mathrm{pcm} 055$

O'Brien, T. P. (1970). "Further observations on hydrolysis of the cell wall in the xylem," Protoplasma 69(1), 1-14. DOI: 10.1007/BF01276648

O'Brien, T. P., and Thimann, K. V. (1967). "Observation on fine structure of oat coleoptiles III. Correlated light and electron microscopy of the vascular tissues," Protoplasma 63, 443-478. DOI: 10.1007/BF01252947

Pilate, G., Déjardin, A., Laurans, F., and Leplé, J.-C. (2004). "Tension wood as a model for functional genomics of wood formation," New Phytol. 164(1), 63-72. DOI: 10.1111/j.1469-8137.2004.01176.x

Saiki, H., and Ono, K. (1971). "Cell wall organization of gelatinous fibers in tension wood," Bulletin of the Kyoto University Forests 42, 210-220.

Sandquist, D., Filonova, L., Schantz, L., Ohlin, M., and Daniel, G. (2010). "Microdistribution of xyloglucan in differentiating poplar cells," BioResources 5(2), 796-807. DOI: 10.15376/biores.5.2.796-807

Wardrop, A. B., and Dadswell, H. E. (1955). "The nature of reaction wood. Variations in cell wall organization of tension wood fibers," Aust. J. Bot. 3(2), 177 189. DOI: $10.1071 /$ BT9550177

Yoshinaga, A., Kusumoto, H., Laurans, F., Pilate, G., and Takabe, K. (2012). "Lignification in poplar tension wood lignified cell wall layers," Tree Physiol. 32(9), 1129-1136. DOI: 10.1093/treephys/tps075

Article submitted: April 19, 2019; Peer review completed: June 23, 2019; Revised version received and accepted: August 1, 2019; Published: August 7, 2019.

DOI: 10.15376/biores.14.4.7675-7686 